\title{
Laser surface texturing of stainless steel 316L cylindrical pins for interference fit applications
}

\author{
Muhannad A. Obeidi ${ }^{1,2}$, Eanna McCarthy ${ }^{1,2}$, Lekshmi Kailas ${ }^{3}$, Dermot Brabazon ${ }^{1,2}$ \\ ${ }^{1}$ Advanced Processing Technology Research Centre, Dublin City University, Dublin 9, Ireland \\ ${ }^{2}$ School of Mechanical \& Manufacturing Engineering, Dublin City University, Dublin 9, Ireland \\ ${ }^{3}$ Materials and Surface Science Institute (MSSI), University of Limerick, Ireland
}

\begin{abstract}
This study is focused on the development of a novel method for designing high-end interference fit fasteners. In this work, a new surface laser treatment process was utilized to enable enhanced usability and bond strength control of press-fit connections. Cylindrical $10 \mathrm{~mm}$ diameter pins of 316L were textured over a $10 \mathrm{~mm}$ length using a pulsed $\mathrm{CO}_{2}$ laser beam focused one millimeter below the surface, with the thermal energy adjusted to bring the surface to just above the melting point of the metal. The pin surface morphology and dimensions were precisely controlled by controlling the laser processing parameters specifically the laser beam power, the pulse repetition frequency, and the overlap between scan tracks. The pin was inserted into a hub hole diameter of $10.05 \pm 0.003 \mathrm{~mm}$ and pull out joint bond strengths were examined. The results of this study showed that surface thus altered provided improved control of the bond strength which is a particular novelty of this new interference fit joining method. Surface roughness, Ra, from 40 to $160 \mu \mathrm{m}$, melt pool depths from 0.4 to $1.7 \mathrm{~mm}$, increases in the pin outer diameter from 0.5 to 1.1 $\mathrm{mm}$, and pull out forces of up to $7.51 \mathrm{kN}$ were achieved. The bond joint was found to re-grip before final failure providing a more secure joint and increased safety. This joining method allows for the possibility of joining different materials. The pulse repetition frequency was measured to be the most significant processing parameter for control of the resulting mechanical properties and the bond strength with a clear inverse relationship.
\end{abstract}

Keywords: Interference fit, Press fit, $\mathrm{CO}_{2}$ laser processing, Stainless steel, Surface texturing, Moiré pattern. 


\section{Introduction}

The interference fit method of joining is widely used in industrial fasteners, for example as part of bolt, rivet, positioning pin, and tapered insertion pin surfaces. They have extensive applications in automotive and aerospace because they are easy to fit, dismantle, replace, or repair. Interference fit, commonly achieved via press or shrink fitting, is used in industrial applications for a hub and shaft coupling assembly, in which the hub hole is machined slightly smaller than the shaft diameter (Norton, 2011). In press fitting, the two parts are forced together during assembly using a press, generally with the presence of lubricant oil. The friction and the difference between the two mating parts' geometry creates a contact pressure. Both the friction force and the contact pressure created depend on the contact area, the coefficient of friction, and the elastic or elastic-plastic deformation of the materials. These forces are responsible for the prevention of sliding or loosening during power transmission from the shaft to the hub (Huyuk et al., 2014). Shrink fitting or cold expansion is also widely used in industry. In this method, a tapered mandrel is inserted in a slightly smaller hole diameter hub from one end all the way to the opposite side. During insertion, a significant plastic deformation is produced in the hole peripheral area. Moving further in the radial direction, an elastic deformation is produce in the material loaded below the yield point (elastic limit). After the insertion, the elastically deformed zone generates a compressive residual stress on the hole circumference. This compression residual stress can significantly delay the initiation and propagation of fatigue cracks (Fu et al., 2015), and prolong the joint lifetime (Shizhen et al., 2015). The technique has been employed and developed by Boeing for some applications, such as the landing gear (Barter and Dixon, 2009) and the engine mountings (Fu et al., 2015). Another common method for interference joining parts is using knurled pins. This method is predominantly applied in die casting, and for the joining of wood, plastic, and thin sections (Parmley, 1989). In the die casting assembly, the knurled pin (mandrel) and the hub are positioned together by tooling while melted zinc alloy is injected into the void between the mating components. The shrinkage of the solidified alloy allows for a strong mechanical joining, for example when joining a mandrel to an abrasive wheel. In the force-inserted knurled pin interference fit method, the knurl leads to two types of joining during insertion. The first is knurl cutting joining, in which the knurl in the pin cuts into the hub due to the axial insertion of the pin into a slightly smaller diameter hub. The second type 
of joining is knurl forming joining, in which a radial displacement is created in the hub generating a high groove bond pressure.

These mechanical joints are often exposed to cyclic loads and may fail by fatigue and crack propagation, as a result of the residual stresses on the pin or the hole during manufacturing and assembly. Studies in the past six decades have tried to innovate a practical solution to this problem with limited implications for the shaft-hub interference, the elastic-plastic deformation calculations, and design. Surface modification has been shown in the literature to allow for the production of components with higher hardness (Yasavol et al., 2013), wear resistance (Rosenkranz et al., 2014), and fatigue life (Szkodo and Bie, 2016). These treatments have a variety of applications in industry and biomedical implants. Improvement of hardness and wear resistance is usually achieved by nitriding, using Physical or Chemical Vapor Deposition methods (PVD or CVD) (Mattox, 2010). Lasers have been used as a heat source in tool steel nitriding (Schaaf, 2002), and have produced useful material properties (Waugh and Lawrence, 2015). Despite the fact that laser nitriding is a complex process, the accurate control of the processing parameters (laser fluence, number of pulses, spot size, and the gas pressure) controls its influence in different materials (Schaaf, 2002). This ability to control the surface hardness and elastic-plastic response profile could be optimized for enhanced control of interference bond strength and life time.

Machinists usually use the limits of $0.025 \mathrm{~mm}$ of interference for shaft diameters of up to $25 \mathrm{~mm}$, and $0.05 \mathrm{~mm}$ for diameters between 25 and $100 \mathrm{~mm}$. The process of manufacture of this high precision interference is carried out on high precision lathe machines, and sometimes also employing cylindrical grinding (externally on the shaft surface) and jig grinding (for the internal grinding of the hole). These finalized dimensions are crucial to providing the exact amount of interference in the design. The quality of the bond, as well as bonding and de-bonding forces, are extremely sensitive to these dimensions. This represents an important drawback for this process, due to the high cost of labor and machining, as well as the potential for poor bonding quality due to surface deterioration or damage from excessive surface deformation. Slight increases in interference can lead to excessive plastic deformation which can lead to premature joint failure. Another drawback to be considered is the difficulty of the assembly or disassembly when maintenance is needed. Depending on the bond strength, the whole assembly might need replacement after one or more maintenance cycles. 
This paper presents a new method of accurately defining the material volume creating the interference fit, such that it provides better physical properties of these joints. A novelty provided from this new interference fit joint design is the ability to achieve pre-defined, tighter tolerance, and more repeatable levels bond forces and bond strengths. These aspects are of particular importance in providing better-defined margins of quality control and safety for applications such as in airplane and automobile manufacturing. In this technique, the fastener pin is created by laser texturing the surface of stainless steel pins. The fastener's surface morphology and dimensions are precisely defined by controlling the working parameters, including laser beam power, laser spot size, pulse repetition frequency (PRF), scanning speed, and the overlap between each scan.

\section{Materials and Method}

Cylindrical 316L stainless steel samples of $10 \mathrm{~mm}$ in diameter and $60 \mathrm{~mm}$ length were prepared. The laser process was carried out using a computerized numerical control (CNC) $\mathrm{CO}_{2}$ laser machine Rofin DC-015 of $1.5 \mathrm{~kW}$ maximum average power, and a laser beam focus diameter of $0.2 \mathrm{~mm}$, with the focal position set at $1 \mathrm{~mm}$ below the sample surface. Hub flanges of the same material were machined to $30 \mathrm{~mm}$ external diameter, and center drilled and reamed to give the final hole diameter of $10.05 \pm 0.003 \mathrm{~mm}$.

Cylindrical samples were employed, instead of flat samples, as this allowed for higher scanning speeds from the resultant velocity vector of the combined angular and translational velocity vectors. The plain samples were first roughened by shot peening to improve the absorption of the laser beam (Bergström et al., 2007). Guyson Honite 13 soda-lime glass bead with particles size of 106-212 micron was used as peening media and the resulting surface roughness was increased from 0.8-1.0 micron to 3.0-3.2 micron. The laser parameters examined were the power (W), pulse repetition frequency PRF $(\mathrm{Hz})$, and the percentage of overlap set for scan pulses $(\%)$. The increase in the sample diameter $(\mathrm{mm})$ resulting from the highly controlled melting and resolidification of the surface metal was recorded. The outer diameter of the pins is increased mainly due to the creation of a new surface profile with a peak and valley texture. The phase transformation from austenite to martensite is also known to have a small increase in volume (Kannatey-Asibu, 2009). The resulting modified surfaces contained texture geometries with predefinable peak-to peak widths, valley-to-peak heights, and texture directions. The method was 
developed and reported by Obeidi et al. (Obeidi et al., 2016). It is shown in this latter work that the surface profile is highly definable and repeatable in terms of increase in pin diameter, surface profile, surface roughness and the resulting moiré pattern. Figure 1 shows a schematic diagram of the laser process utilized in this study. The cylindrical pin samples were rotated using a DC motor that provided an angular speed range from 0 to $5000 \mathrm{rpm}$. The sample carrying stage provided translational speed within the range of 0 to $5000 \mathrm{~mm} / \mathrm{min}$. Argon gas was delivered in line with the laser beam during processing. The role of the assist gas was to protect the laser focusing lens from the laser-induced plasma, which may harm the lens, and also to provide an inert gas shrouding to reduce the sample surface oxidation.

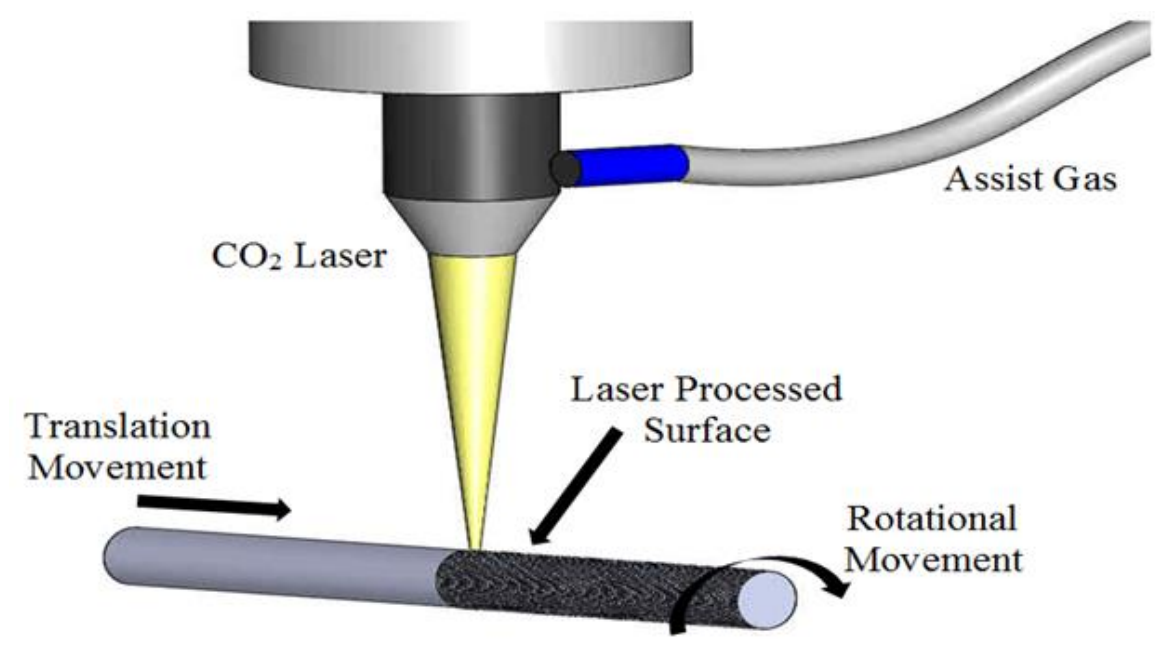

Figure 1 Schematic diagram for the $\mathrm{CO}_{2}$ laser scanning process of stainless steel 316L cylindrical samples (Obeidi et al., 2016).

Figure 2 shows a schematic diagram for the resulting textured pin sample and the hub ring. The hub rings were manufactured to the final dimension using high precision CNC lathe machines, and the hole was reamed to the required diameter of $10.05 \pm 0.003 \mathrm{~mm}$. The hole was chamfered on one end at $45^{\circ}$ for the ease of pin insertion and to reduce the destruction of the textured material by shear during insertion. The hub thickness and the chamfer angle were adjusted to keep the full engagement length between the two mating parts at $10 \mathrm{~mm}$ in length. 


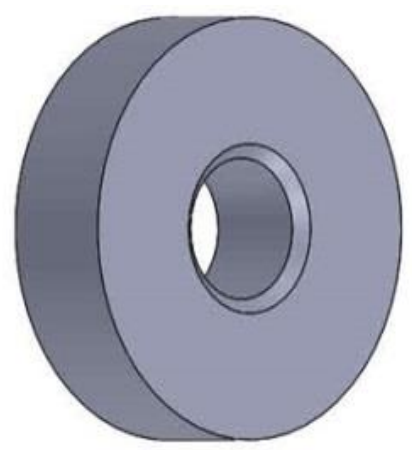

Hub

\section{Unprocessed surface}

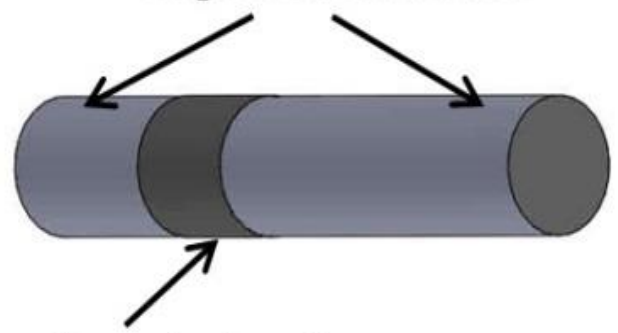

Laser textured

surface

Figure 2 Schematic of laser textured insertion pin and the corresponding hub.

The assist gas pressure was tested at different levels, and the increase in diameter, presence of oxidation, roughness, and moiré pattern profile were recorded. From a preliminary assessment test, an optimum argon gas pressure of $0.3 \mathrm{MPa}$ was identified and applied for all of the samples produced in this study. This gas pressure resulted in an acceptable increase in pin diameter, a better visual textured pattern, and a reduced appearance of oxide.

The laser surface texturing was carried out by controlled melting and re-solidification of a section of $10 \mathrm{~mm}$ in length on each cylindrical sample, using a set of laser processing parameters defined according to a $3^{3}$ factorial design of experiments (DoE). The laser processing parameters settings for the implemented design of experiments are presented in Table 1.

Table 1 The laser processing parameters implemented corresponding to full $3^{3}$ DoE.

\begin{tabular}{|c|c|c|c|}
\hline Processing parameter & Level - 1 & Level - 2 & Level - 3 \\
\hline Power $(\mathbf{W})$ & $\mathbf{3 0 0}$ & 400 & $\mathbf{5 0 0}$ \\
\hline Frequency $(\mathrm{Hz})$ & 100 & 200 & 300 \\
\hline $\begin{array}{c}\text { Overlapping } \\
\text { scan tracks }(\%)\end{array}$ & -20 & 0 & 20 \\
\hline
\end{tabular}

\subsection{Microstructure and surface profile measurement}

The produced samples were cross sectioned and prepared for the microstructure analysis using a CNC wire EDM cutting machine. The wire cutting method was preferred over other traditional methods in order to avoid damaging the laser-processed area and to aid metallographic quality 
surfaces to be produced. A Buehler Motopol 2000 was used during the grinding and polishing process. The grinding was carried out by applying successive grades of silicon carbide papers of 400, 600, 800 and 1200 with the presence of water as a lubricant and for the flushing of the loose metal and abrasive particles. Final polishing was carried out using Textmet cloth with diamond and alumina suspension of 9, 6, 3 and $0.05 \mu \mathrm{m}$ particle size. Each polishing grade was applied for 3 to 4 minutes with rotational speed of $250 \mathrm{rpm}$. The total thickness of the layer removed from each sample from the grinding and polishing steps was greater than $500 \mu \mathrm{m}$. For the implemented wire EDM process, the thermally affected layers would be much smaller than 500 $\mu \mathrm{m}$. The grinding and polishing process would therefore remove any EDM related microstructure effects.

Stainless steel 316L, as an austenitic steel alloy is significantly anti-corrosive and is difficult to etch. Glyceregia etchant was used to reveal the grain boundaries and orientation for the set of samples in the DoE. Glyceregia was made up of $20 \mathrm{ml}$ nitric acid, $30 \mathrm{ml}$ hydrochloric acid and $20 \mathrm{ml}$ glycerol and was applied for 5 to $7 \mathrm{sec}$ by swabbing the cross section area (Khan and Debroy, 1985). After the chemical etching, the sample was primarily washed using tap water and liquid soap solution to remove any residual chemical substances and finally with isopropyl alcohol to remove any stains or prints of water and soap. A Carl-Zeiss EVO-LS15 SEM was used to reveal the modified microstructure of the cross section and the surface topology. The resulting average surface roughness of the produced samples was measured using a Keyence VHX2000E 3D digital microscope.

\subsection{Elastic modulus and hardness measurement}

The elastic modulus in the produced samples was measured and related to the laser processing parameters. The test was performed using the Agilent G200 nano-indenter under Continuous Stiffness Measurement (CSM) mode of operation. Indentation was carried out in three lines on the cross section surface of each sample starting from one side to the other through the center of the sample, see Figure 3. Each line of indentations comprised of 45 indents with $200 \mu \mathrm{m}$ spacing between each indent and also between the three lines. A total of 135 indents were thereby made on each sample. A Berkovich nano-indenter of three sides with an enclosed angle of $142.5^{\circ}$ was used to produce indents of a triangular impression. 


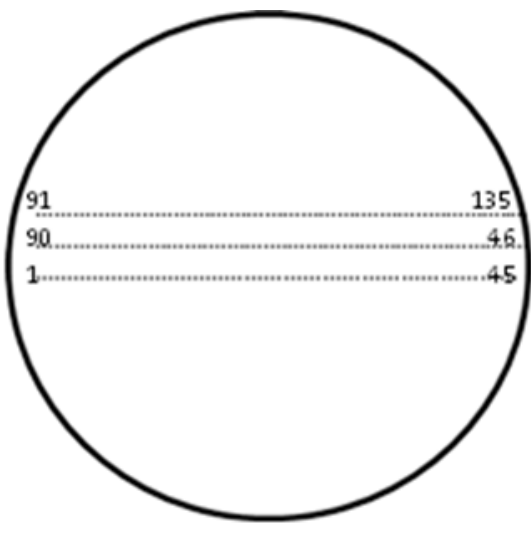

(a)

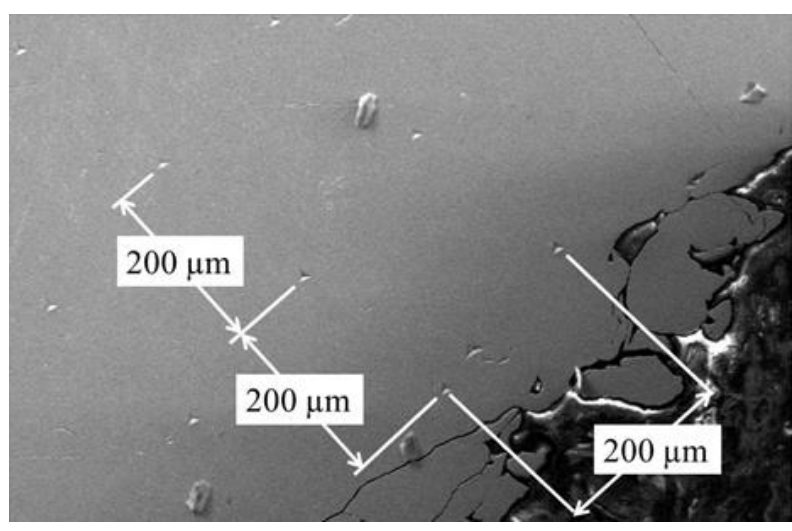

(b)

Figure 3 (a) The methodology used in nano-indentation and

(b) SEM micrograph for the indents.

The Agilent G200 was used to record load-displacement data from each indent to a depth of 2 $\mu \mathrm{m}$ at a rate of $10 \mathrm{~nm} / \mathrm{sec}$. A holding time of $10 \mathrm{sec}$ was applied once the maximum depth was reached. The same rate of $10 \mathrm{~nm} / \mathrm{sec}$ was applied during unloading with a holding time of 100 sec when the load was $10 \%$ of the maximum load reached. The resulting variation in the elastic moduli are reported and plotted with reference to each indent depth and position on the cross sectional area.

\subsection{Insertion-pull out tests}

The insertion and pull-out forces were measured using a Zwick Z-50 testing machine with the Zwick TestXpert simulation software. The laser textured SST pins, of initial diameter $10 \mathrm{~mm}$, were inserted into SST hub rings with an internal diameter of $10.05 \mathrm{~mm}$ (see Figure 2). Both tests were carried out using speed of $5 \mathrm{~mm} / \mathrm{min}$. The two mating parts were vertically aligned by means of two holders along the main axis of the testing machine. The lower steel holder was used to hold the ring hub, while the insertion pin was rigidly held by means of a collet holder assembly mounted on the upper moving head, see Figure 4. The sample was inserted and the removed using these speeds with 30 seconds of insertion holding time. 


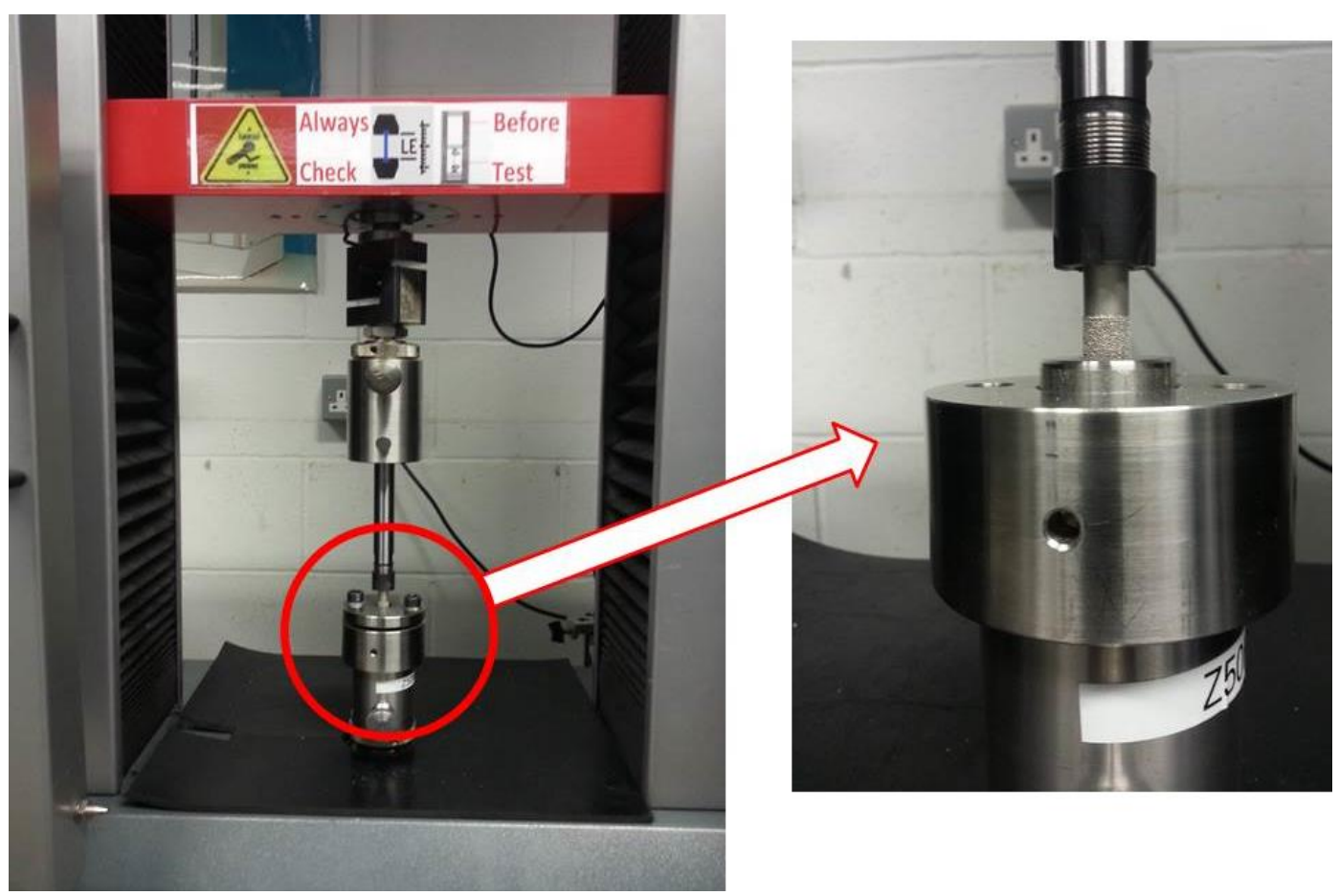

Figure 4 Picture of the insertion and removal test arrangement on the Zwick Z-50.

\section{Results}

Figure 5 (a) shows the stainless steel plain and roughened samples. The laser textured sample is shown in Figure 5 (b); and Figure 5 (c) shows the samples after the insertion and pull-out test. The tested samples exhibit a versatile range of insertion and removal forces synthesized to the main laser processing parameters. The sample from the DoE which gave the highest bond force was sample $9(400 \mathrm{~W}, 100 \mathrm{~Hz},-20 \%)$ and that which gave the lowest bond force was sample 15 (400W, $300 \mathrm{~Hz}, 20 \%)$ in the DoE, respectively.
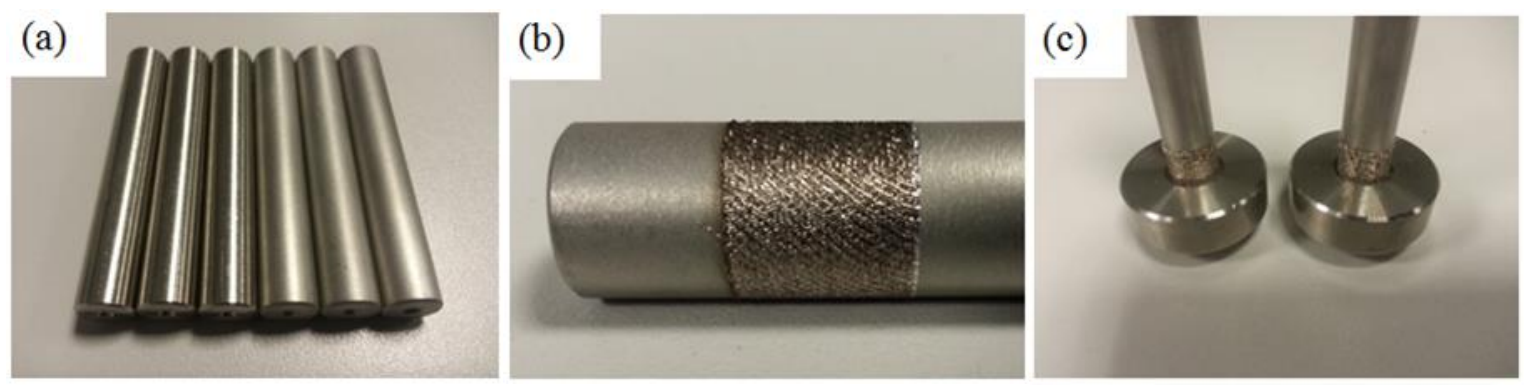

Figure 5 (a) 316L as-received samples (left) and after roughening by shot peening (right),

(b) laser textured sample, and (c) samples after the insertion and pull-out test. 


\subsection{Diameter increase}

The outer diameter of the pins is increased due to the creation of a peak and valley texture at the surface, and a change in the microstructure from austenite to larger volume martensite phase (Kannatey-Asibu, 2009). The resultant increase in samples diameter with the 95\% confidence interval (CI) bars is shown in Figure 6. For this, the average of ten measurements on each sample diameter were taken using a Vernier of $0.05 \mathrm{~mm}$ resolution. The textures, and the outer diameters measured, were consistent longitudinally and circumferentially.

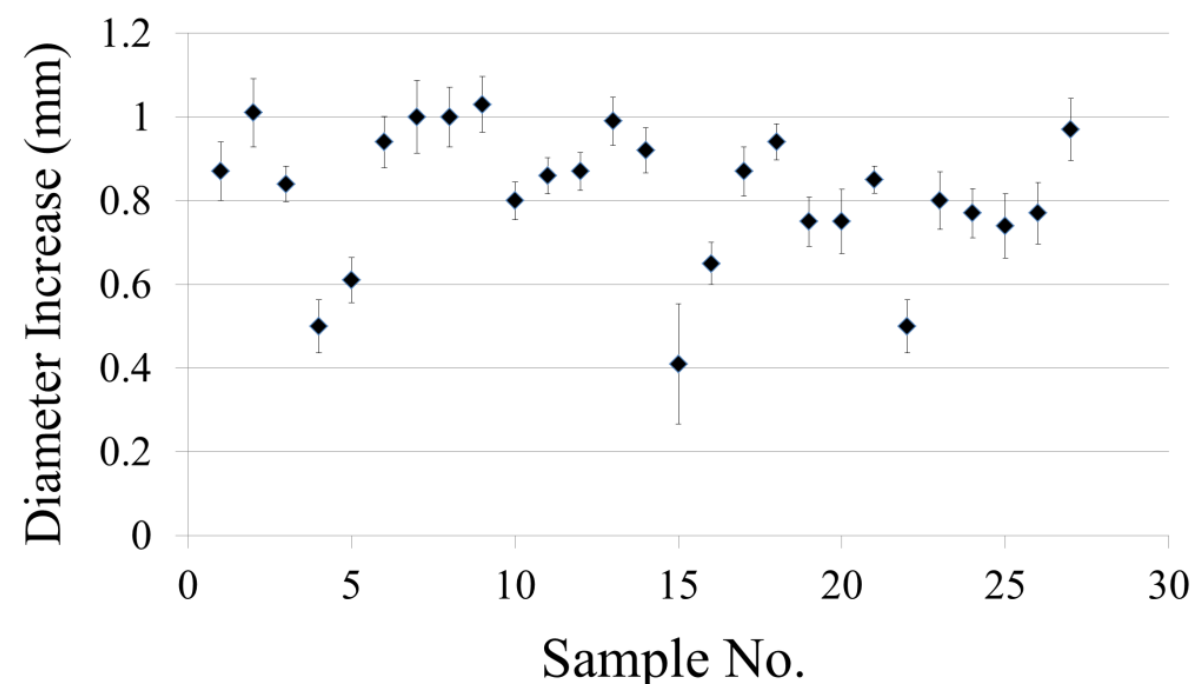

Figure 6 Average diameter increase for samples; 95\% CI bars indicated, $\mathrm{n}=10$.

\subsection{Microstructure and surface profile investigation results}

The measured surface roughness data with the 95\% CI bars are shown in Figure 7 and the correlation between the surface roughness and laser processing parameters is shown in, Figure 8. It is clear from Figure 8 that there is a wide range of control over surface roughness. 


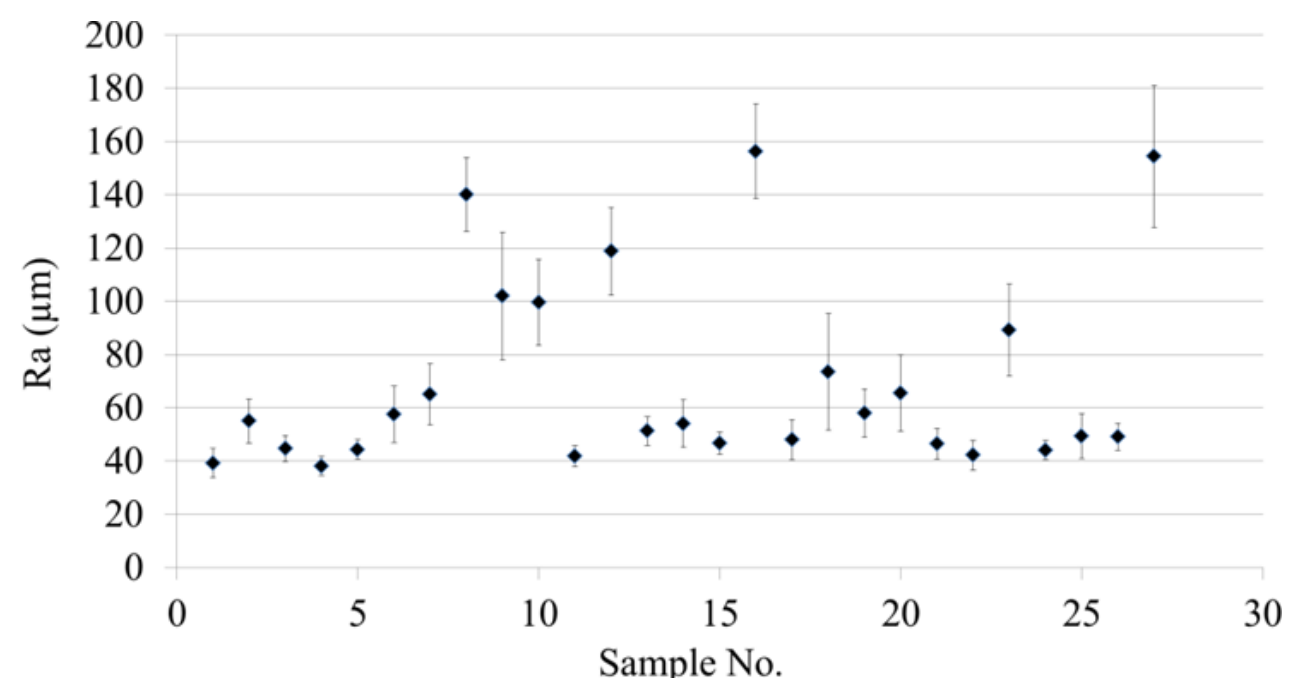

Figure 7 Recorded average surface roughness, $\mathrm{n}=5$.

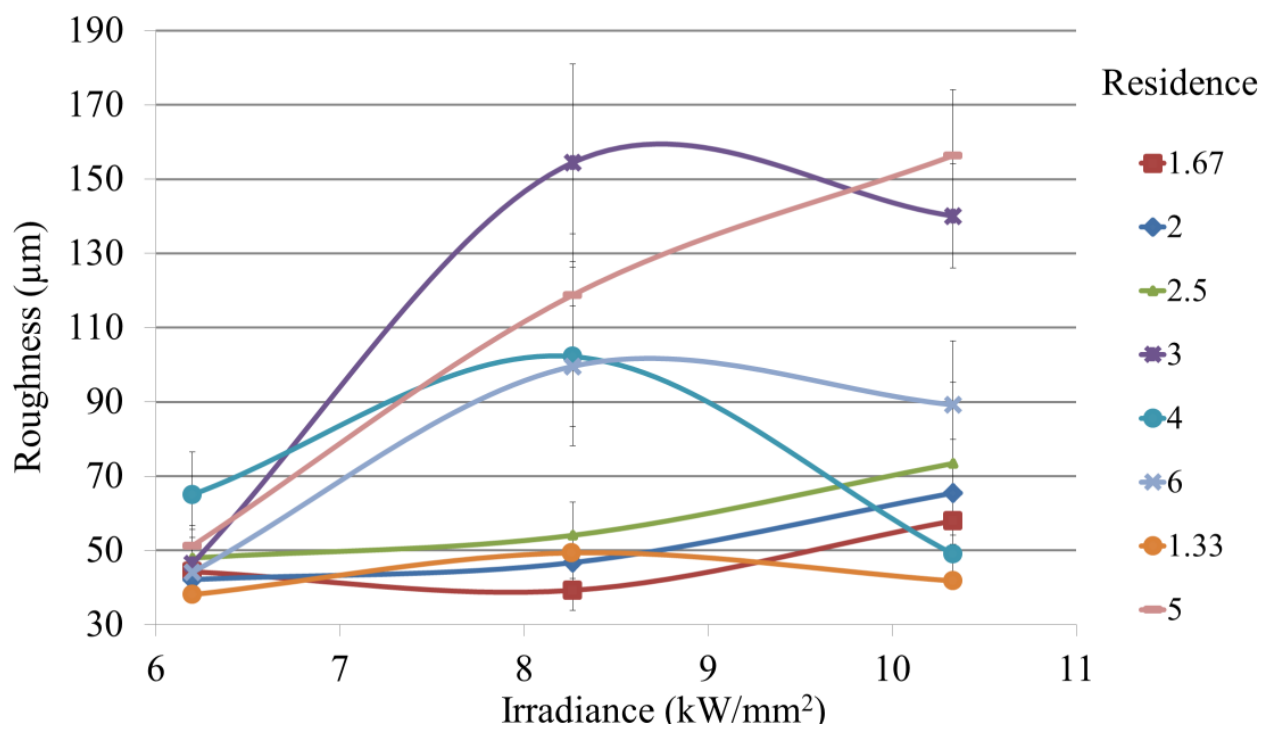

Figure 8 Graph of the recorded surface roughness against the laser irradiance, for various laser residence times, $\mathrm{n}=5$.

Figure 8 indicates that lower roughness levels occurred at lower levels of irradiance. The high levels of irradiance and residence time exhibited wider ranges of roughness, due to the resulting larger melt pool sizes and the gas jet effect in spreading the molten material. The variances in the surface roughness and the melt depth for samples 9 and 15 for example can be seen in the surface morphology and the cross section SEM micrographs listed in Figure 9, respectively. The aforementioned samples were processed by $(400 \mathrm{~W}, 100 \mathrm{~Hz},-20 \%)$ and $(400 \mathrm{~W}, 300 \mathrm{~Hz}, 20 \%)$ 
respectively. These two samples were considered here because they exhibited the maximum and minimum pull-out forces of $17 \mathrm{kN}$ and $0.17 \mathrm{kN}$ respectively, see Figure 11 and Figure 12.

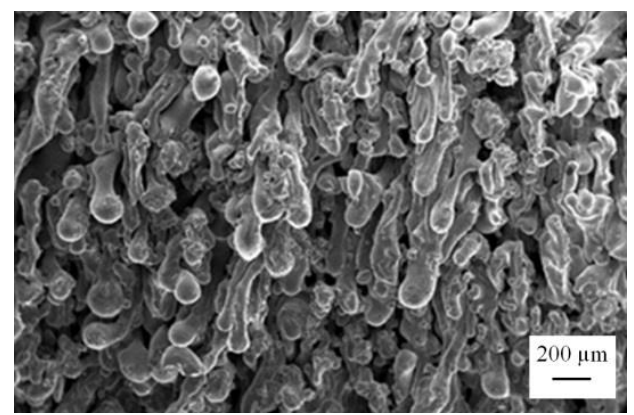

(a)

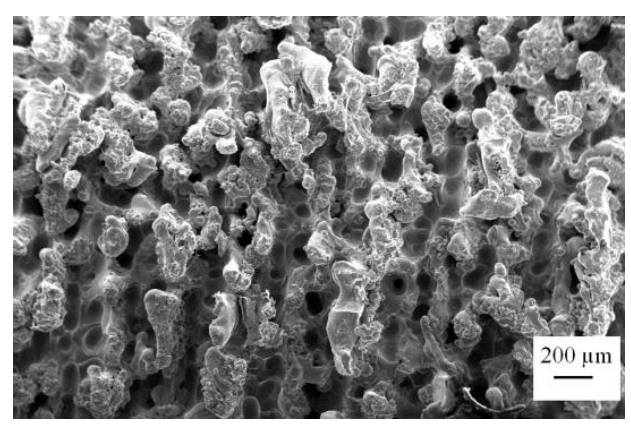

(c)

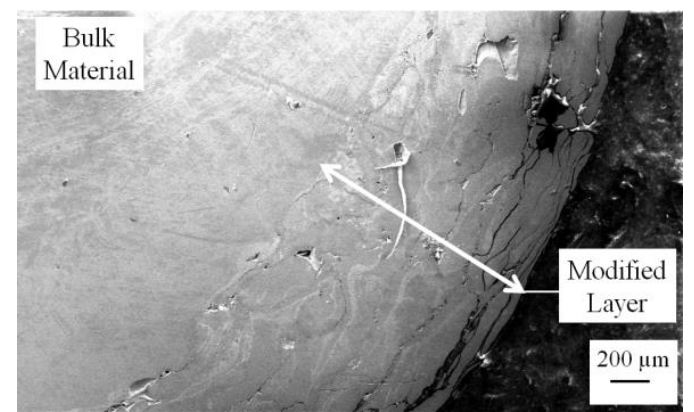

(b)

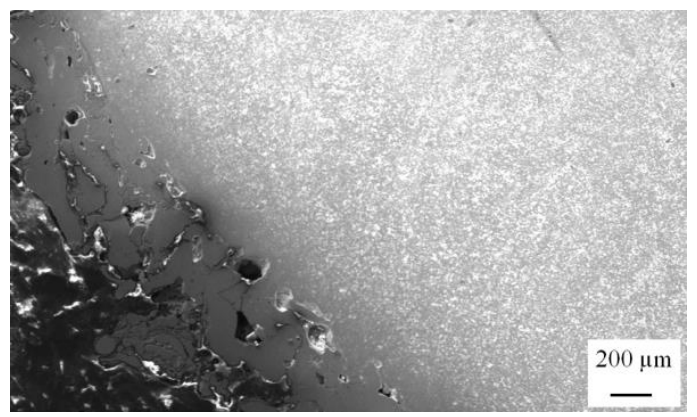

(d)

Figure 9 Surface morphology and cross section view for samples 9 and 15. (a) Surface morphology and (b) cross section microstructure of sample 9 processed with $400 \mathrm{~W}, 100 \mathrm{~Hz}, 4$ $\mathrm{ms}$ and $8.26 \mathrm{~kW} / \mathrm{mm}^{2}, \mathrm{Ra}=102 \mu \mathrm{m}$; (c) surface morphology, and (d) cross section microstructure of sample 15 processed with $400 \mathrm{~W}, 300 \mathrm{~Hz}, 2.0 \mathrm{~ms}$ and $8.26 \mathrm{~kW} / \mathrm{mm}^{2}, \mathrm{Ra}=46.74 \mu \mathrm{m}$.

\subsection{Elastic modulus and nano-hardness results}

No significant changes in the elastic modulus or the hardness were found in the modified layer compared to the untreated bulk material for all the samples in the DoE, see Figure 10 for the data obtained from sample 15 as an example. The data in Figure 10 was recorded for each indent using the method detailed in the materials and methods section, and by averaging the data collected for the indentation depth between 800 to $1800 \mathrm{~nm}$. This arrangement was used in order 
to avoid any error which might be resulted from the vibration associated when the indenter approaches the surface.

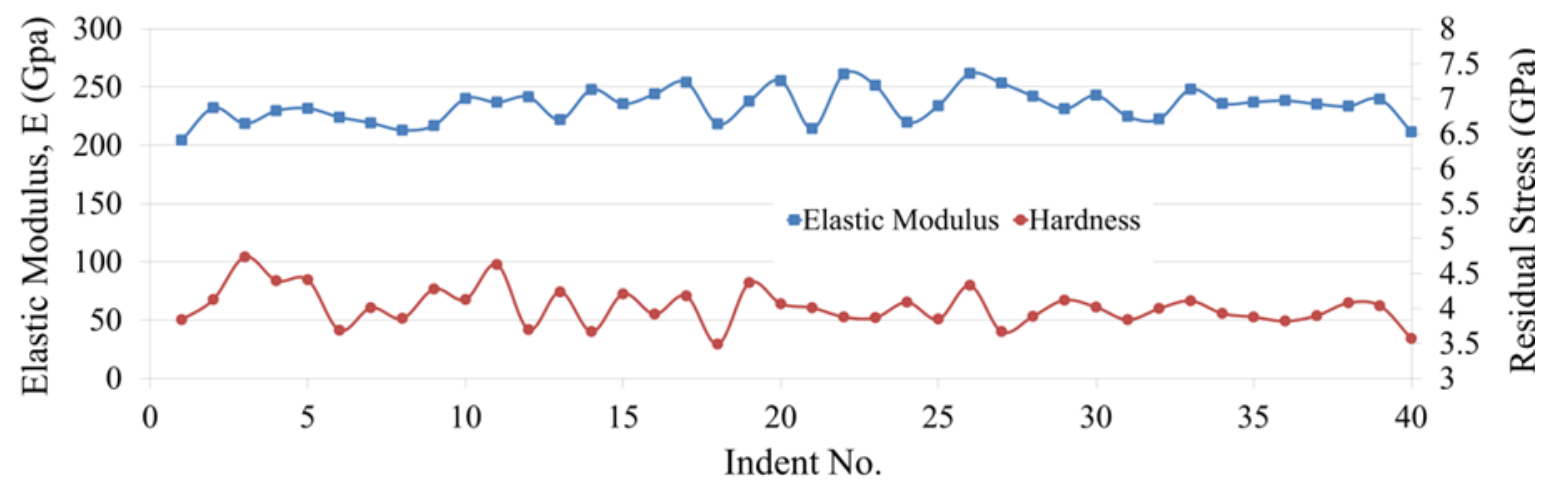

Figure 10 The average elastic modulus and hardness for sample 15.

The average values of the elastic modulus were found to be $238.4 \mathrm{GPa}$ with $2.22 \% \mathrm{CI}$ for sample 9 and $232.8 \mathrm{GPa}$ with $2.75 \%$ CI for sample 15 . The nano-hardness was found to be 4.24 GPa with $0.073 \% \mathrm{CI}$ and $4.14 \mathrm{GPa}$ with $0.06 \% \mathrm{CI}$ respectively. The data indicates that there is no significant change in the surface mechanical properties.

The creation of an altered surface layer would typically lead to entrained surface residual stresses for most steels. However, 316L stainless steel has a ductile austenite structure, which can expand and relax to accommodate the larger volume martensitic phase created by the laser treatment.

\subsection{Insertion-pull out test results}

The insertion and pull-out forces versus the insertion length were obtained and plotted for the full DoE set of samples. Figure 11 shows the insertion and removal plots for eight samples from the DoE set. Each sample was repeated at least three times. Figure 12 shows the plots for sample 9 with $95 \%$ confidence intervals, measured for eight repeated samples. The confidence interval is tight on the insertion plot. For the removal plot, the confidence interval is small before the initial breaking point, after which the joint is loose which results in a more chaotic load bearing level. For sample 9, the scatter in the maximum load at the first breaking point after $0.6 \mathrm{~mm}$, for the eight samples tested was from $5.16 \mathrm{kN}$ to $7.74 \mathrm{kN}$. As can be seen in Figure 12 (b), the load was found to increase again after this initial breakage. 
For comparison, a standard $10 \mathrm{~mm}$ diameter case hardened mild steel dowel was inserted into and removed from a ring of $9.99 \mathrm{~mm}$ internal diameter. The size difference was chosen based on the interference fit standard of having 1/1000th the shaft diameter of interference (Norton, 2011). This gave an average removal force was $6.72 \mathrm{kN}$ for seven repeated samples. The removal force for the dowels droped off linearly after the initial peak. For the laser textured fasteners (shown in Figure 11 (b) and 12 (b)) the force remains higher after the initial peak, typically about half of the peak value, and in many cases the force increased towards the end of the removal. The $95 \%$ confidence interval for the initial peak was $2.20 \mathrm{kN}$ for the dowel samples, and $1.61 \mathrm{kN}$ for the laser textured sample with the highest removal force (sample 9), for the same number of replicates.

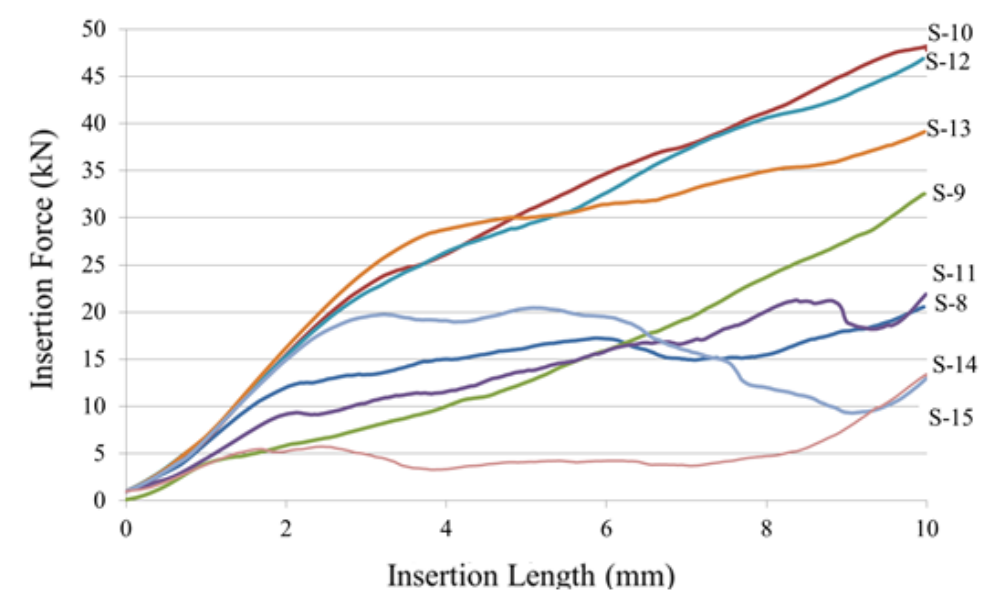

(a)

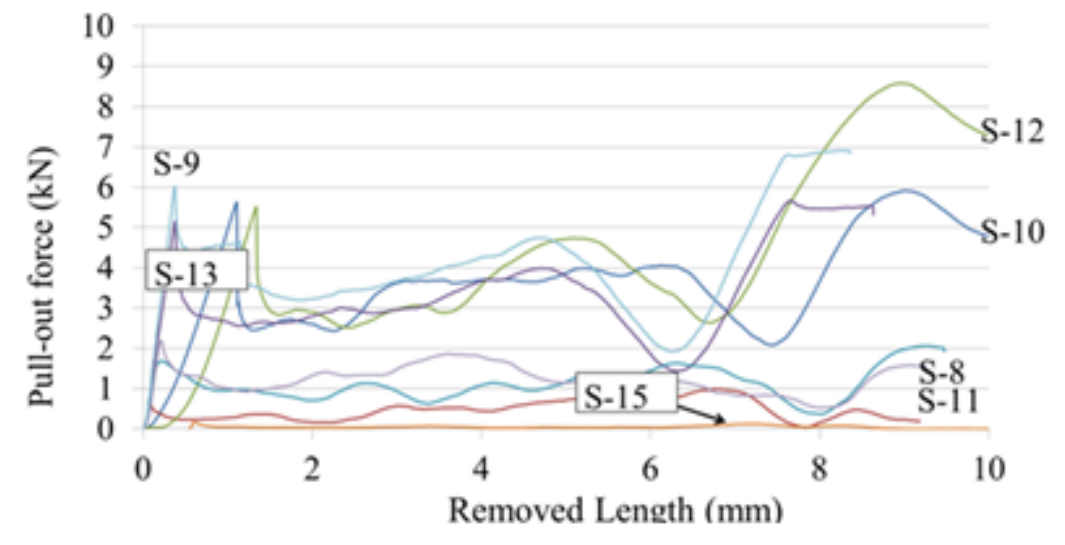

(b)

Figure 11 Graphs of the (a) insertion and (b) removal force against length for eight samples from the DoE. 


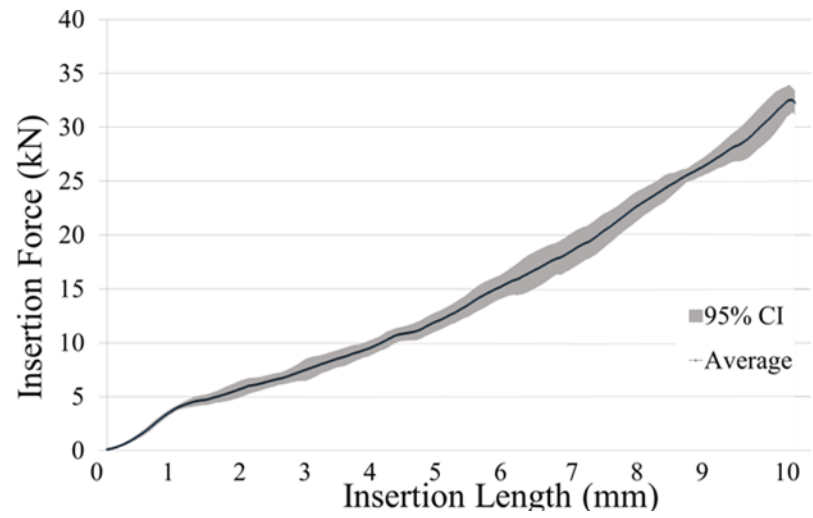

(a)

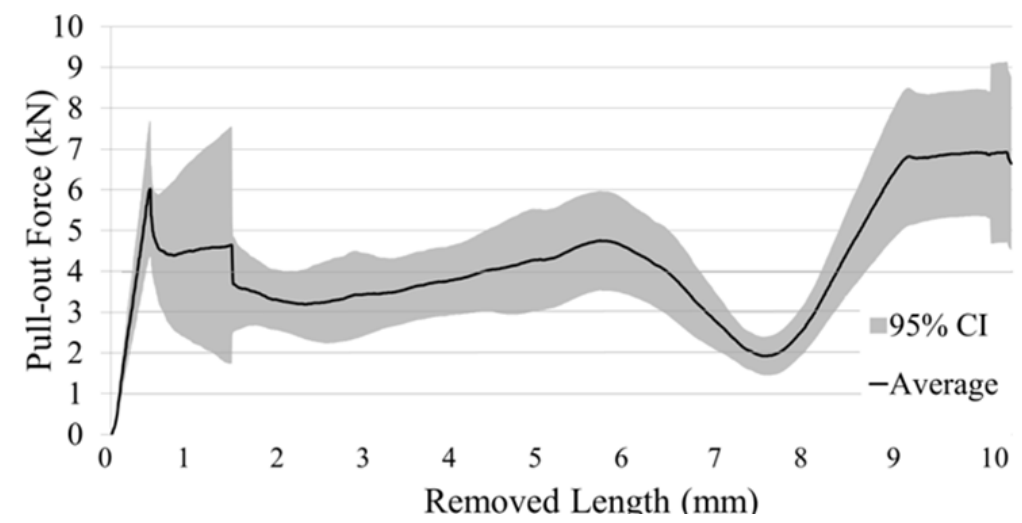

(b)

Figure 12 Graphs of the (a) insertion and (b) removal force against length for sample 9 with the $95 \% \mathrm{CI}$ at each length shown in the shaded region, $\mathrm{n}=8$.

Figure 13 and Figure 14 show the response surfaces (RSM) graphs for the insertion and pull-out forces respectively, plotted for the main laser processing parameters. 


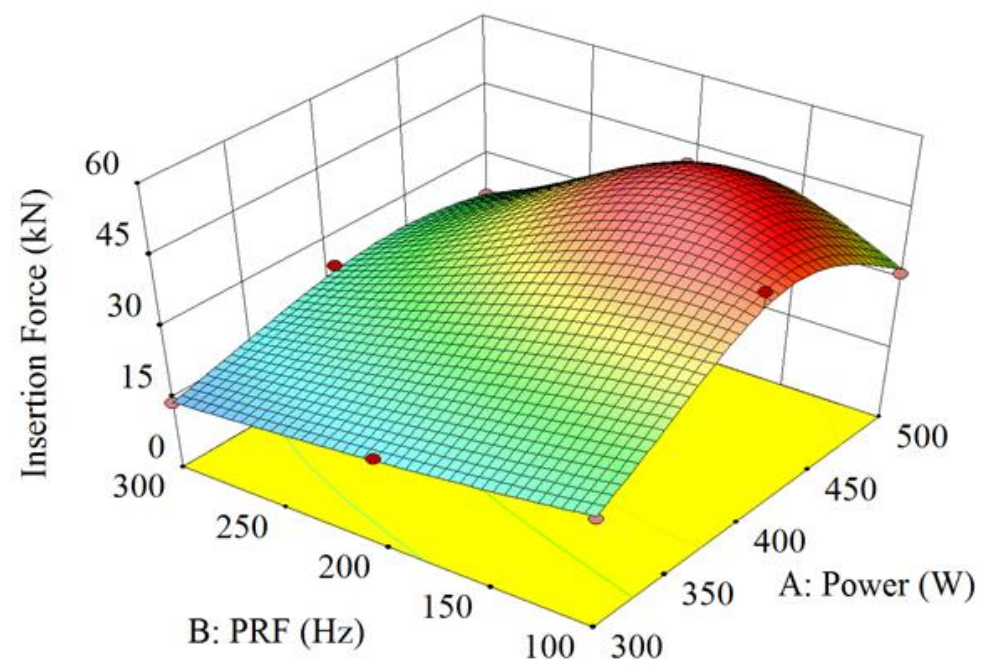

Figure 13 Response surface for insertion force indicating the effects of PRF and power on the insertion force at $-20 \%$ overlap.

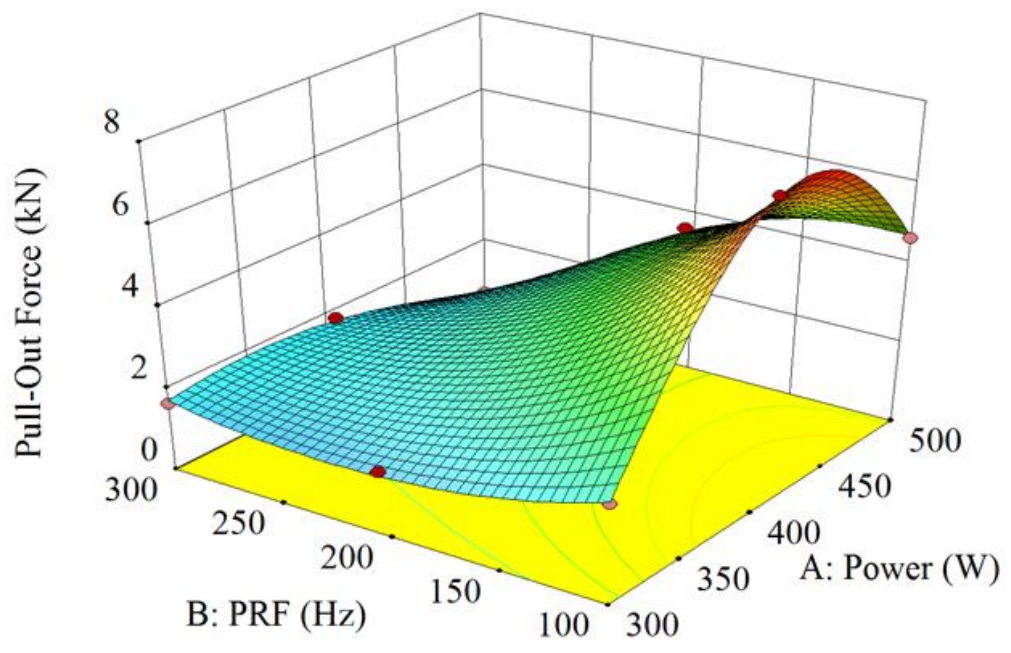

(a) 


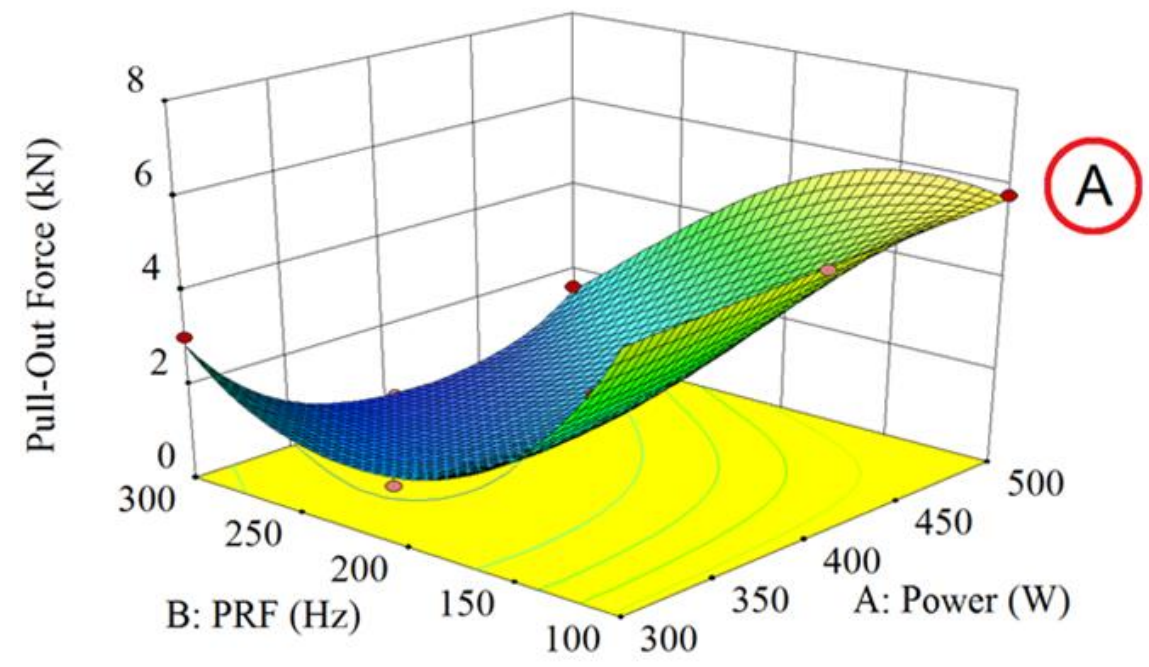

(b)

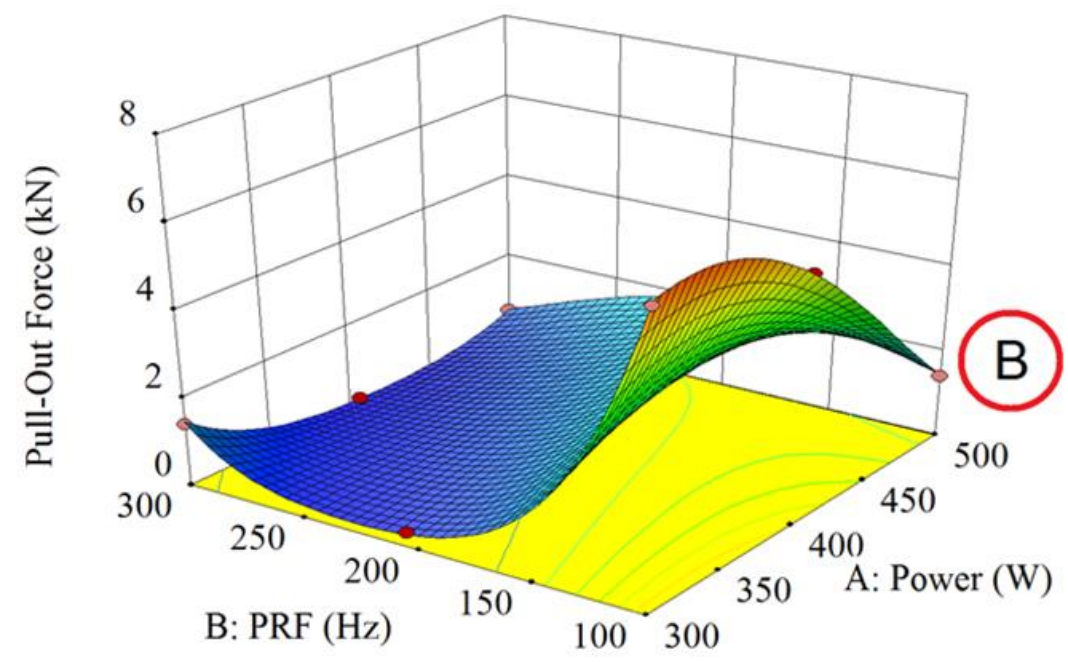

(c)

Figure 14 Response surface for the pull-out force for the laser processing parameters at (a) $-20 \%$, (b) $0 \%$, and (c) $20 \%$ overlap.

The correlation strength (r) between the diameter increase, insertion, and the pull out forces as the resulting responses and the main laser processing parameters were calculated using the Pearson correlation coefficient standard method. On a range of -1 to 1 , the higher the absolute value of $r$ the stronger the correlation with the direction of proportionality indicated by the $(-/+)$ sign. Table 2 lists these correlations with the significance of each correlation measured by the $\mathrm{p}$ 
value. The strongest and most significant correlations were indicated by absolute $r$-values of greater than 0.35 and p-values of less than 0.05 ; these are highlighted and marked with asterisks in Table 2.

Table 2 The correlation strength (r) and the significance of correlation (p) of the process parameters, and resulting profile and force measurements.

\begin{tabular}{|c|c|c|c|}
\hline & $\begin{array}{l}\text { Diameter } \\
\text { Increase }\end{array}$ & $\begin{array}{l}\text { Insertion } \\
\text { Force }\end{array}$ & $\begin{array}{l}\text { Pull-Out } \\
\text { Force }\end{array}$ \\
\hline $\begin{array}{ll}\text { Power } & r= \\
& p=\end{array}$ & $\begin{array}{c}0.11 \\
0.598\end{array}$ & $\begin{array}{c}0.21 \\
0.294\end{array}$ & $\begin{array}{c}0.03 \\
0.866\end{array}$ \\
\hline PRF & $\begin{array}{c}-0.46^{*} \\
0.0147^{*}\end{array}$ & $\begin{array}{c}-0.72^{*} \\
2.4 \times 10^{-5 *}\end{array}$ & $\begin{array}{c}-0.72 * \\
2.1 \times 10^{-5 *} \\
\end{array}$ \\
\hline OV\% & $\begin{array}{l}-0.16 \\
0.427\end{array}$ & $\begin{array}{l}-0.29 \\
0.138 \\
\end{array}$ & $\begin{array}{l}-0.16 \\
0.415 \\
\end{array}$ \\
\hline Pulse Energy & $\begin{array}{c}0.25 \\
0.216\end{array}$ & $\begin{array}{c}0.69^{*} \\
7.7 \times 10^{-5 *}\end{array}$ & $\begin{array}{c}0.68^{*} \\
1 \times 10^{-4 *}\end{array}$ \\
\hline Energy Density & $\begin{array}{c}0.16 \\
0.431\end{array}$ & $\begin{array}{c}0.55^{*} \\
2.7 \times 10^{-3 *}\end{array}$ & $\begin{array}{c}0.58^{*} \\
1.6 \times 10^{-3 *}\end{array}$ \\
\hline Fluence & $\begin{array}{l}0.25 \\
0.21\end{array}$ & $\begin{array}{c}0.69^{*} \\
7.7 \times 10^{-5 *}\end{array}$ & $\begin{array}{c}0.67^{*} \\
1 \times 10^{-4 *}\end{array}$ \\
\hline Diameter Increase & & $\begin{array}{l}0.42 * \\
0.03 *\end{array}$ & $\begin{array}{l}0.24 \\
0.22 \\
\end{array}$ \\
\hline Insertion Force & $\begin{array}{l}0.42 * \\
0.03 *\end{array}$ & & $\begin{array}{c}0.91^{*} \\
4.7 \times 10^{-11 *}\end{array}$ \\
\hline Pull-Out Force & $\begin{array}{l}0.42 \\
0.22 \\
\end{array}$ & $\begin{array}{c}0.91^{*} \\
4.7 \times 10^{-11 *} \\
\end{array}$ & \\
\hline
\end{tabular}

Figure 15 shows SEM images of the surface morphology and the cross section microstructure of un-treated sample. The dark regions in Figure 15 (a) indicate martensite formed by the coldworking during manufacturing (ASM Handbooks, 1985). Figure 15 (b) shows the austenitic microstructure of the samples at room temperature in the cross section view. The small pores present in the cross section could be explained by the impurities and inclusions that been removed during polishing and the chemical etching. The grain boundaries in the cross section view were revealed by etching with glyceregia (ASM Handbooks, 1985). 

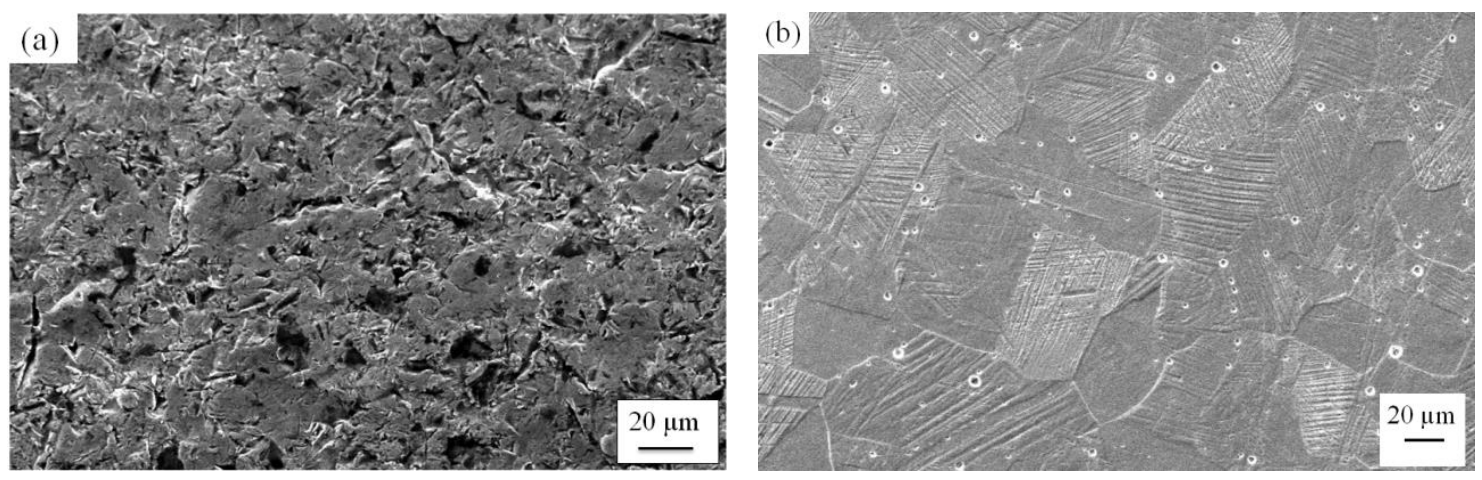

Figure 15 316L Un-treated sample (a) surface morphology and (b) SEM image for the cross section revealed with glyceregia etchant.

Figure 16 and Figure 17 show SEM images for samples 9 and 15, respectively. The melted, resolidified zone and its boundary for sample 9 are shown in Figure 16. Area 1 in Figure 16 indicates the re-solidified region and area 2 is the bulk metal.

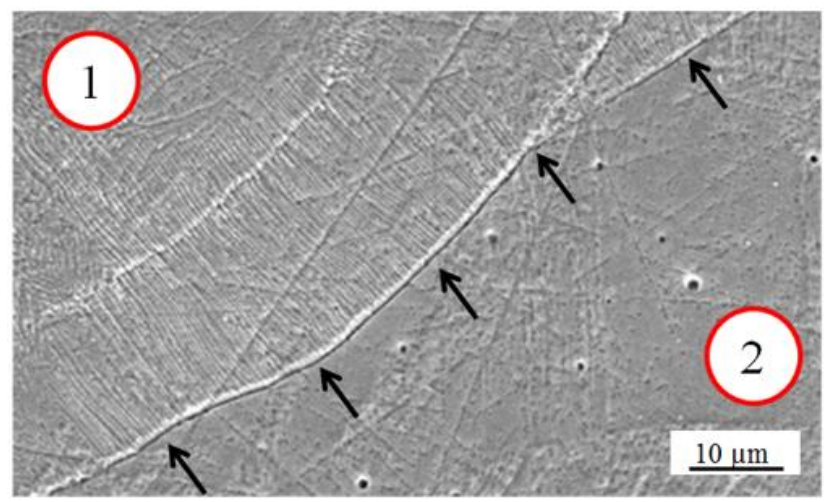

Figure 16 Micrograph of the cross section microstructure at the boundary between the meltpool and bulk for sample 9 processed with residence time of $4 \mathrm{~ms}$, and power density of $826 \mathrm{~kW} / \mathrm{cm}^{2}$, revealed by glyceregia etchant.

Sample 15, shown in Figure 17, was processed with $500 \mathrm{~W}, 300 \mathrm{~Hz}$ and $-20 \%$ OV and a resulting residence time of $1.33 \mathrm{~ms}$ and power density of $1033 \mathrm{~kW} / \mathrm{cm}^{2}$. 


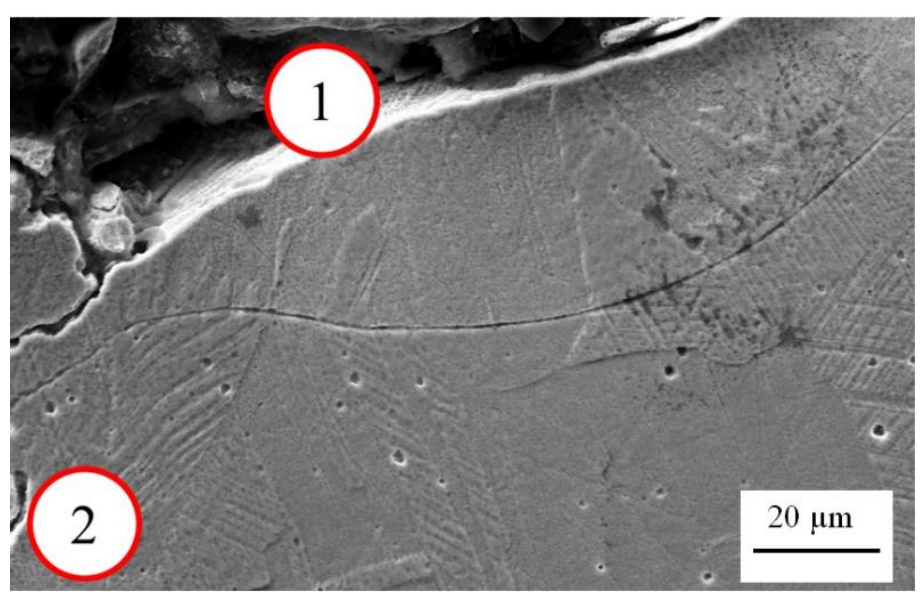

Figure 17 Micrograph of the cross section microstructure for sample 15 showing the early stage of the meltpool close to the surface, the processing residence time $1.33 \mathrm{~ms}$ and power density $1033 \mathrm{~kW} / \mathrm{cm}^{2}$; area 1 indicates the re-solidified region and area 2 the bulk metal, revealed by glyceregia.

The meltpool depth was also investigated for the full set of DoE samples. SEM images were taken for the processed samples showing the re-solidified zone and the modified layer depth, see Figure 9 (b). Eight measurements for the melt pool depth were taken on each sample, averaged and plotted versus the residence time with the 95\% CI bars as shown in Figure 18 below. As residence time increased, the melt pool depth also increased.

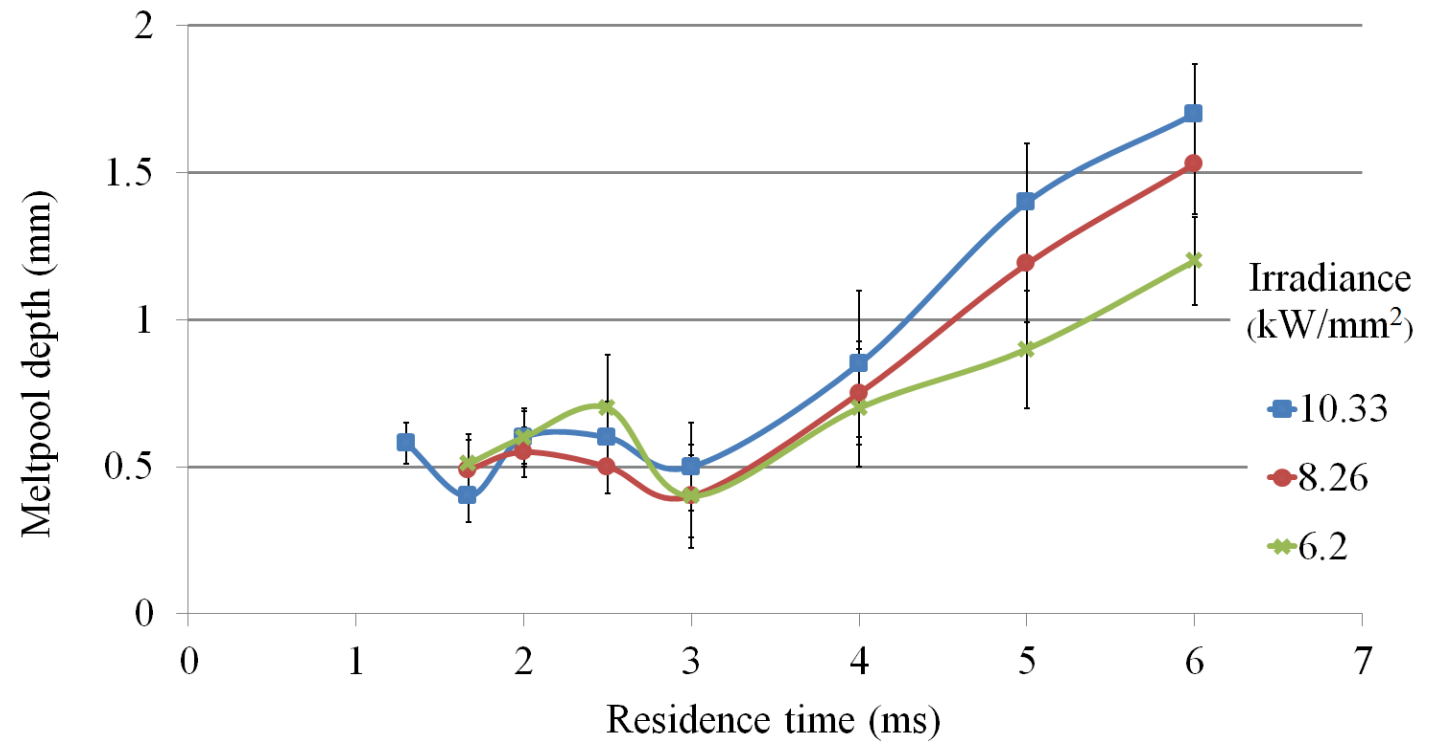

Figure 18 Graph of the melt pool depth versus residence time for various levels of irradiance, $n=8$. 


\section{Discussion}

\subsection{Pull-out force results}

In this paper, the results of a full $3^{3}$ DoE set of samples were presented for the interference-fit application, and both insertion and removal force were measured and analyzed. A wide range of forces were recorded related to the different laser processing parameters and the change in surface mechanical and physical properties. The resulting average surface roughness shows a large variation of values which can be explained with reference to the calculated laser processing parameters, see Figure 8. This graph shows the high surface roughness at high levels of irradiance and residence time due to the longer exposure time. This result was also shown by Pinkerton and Li (Pinkerton and Li, 2003) and Chikarakara (Chikarakara et al., 2011). The higher surface roughness was noted when a residence time of $>3 \mathrm{~ms}$ and irradiance of $>8.26$ $\mathrm{kW} / \mathrm{mm}^{2}$ was applied. At these conditions the highest level of melting and material removal resulted causing degradation in surface roughness when higher thermal energy and exposure time were employed. Figure 19 shows the scattering of the pull-out force versus the surface roughness.

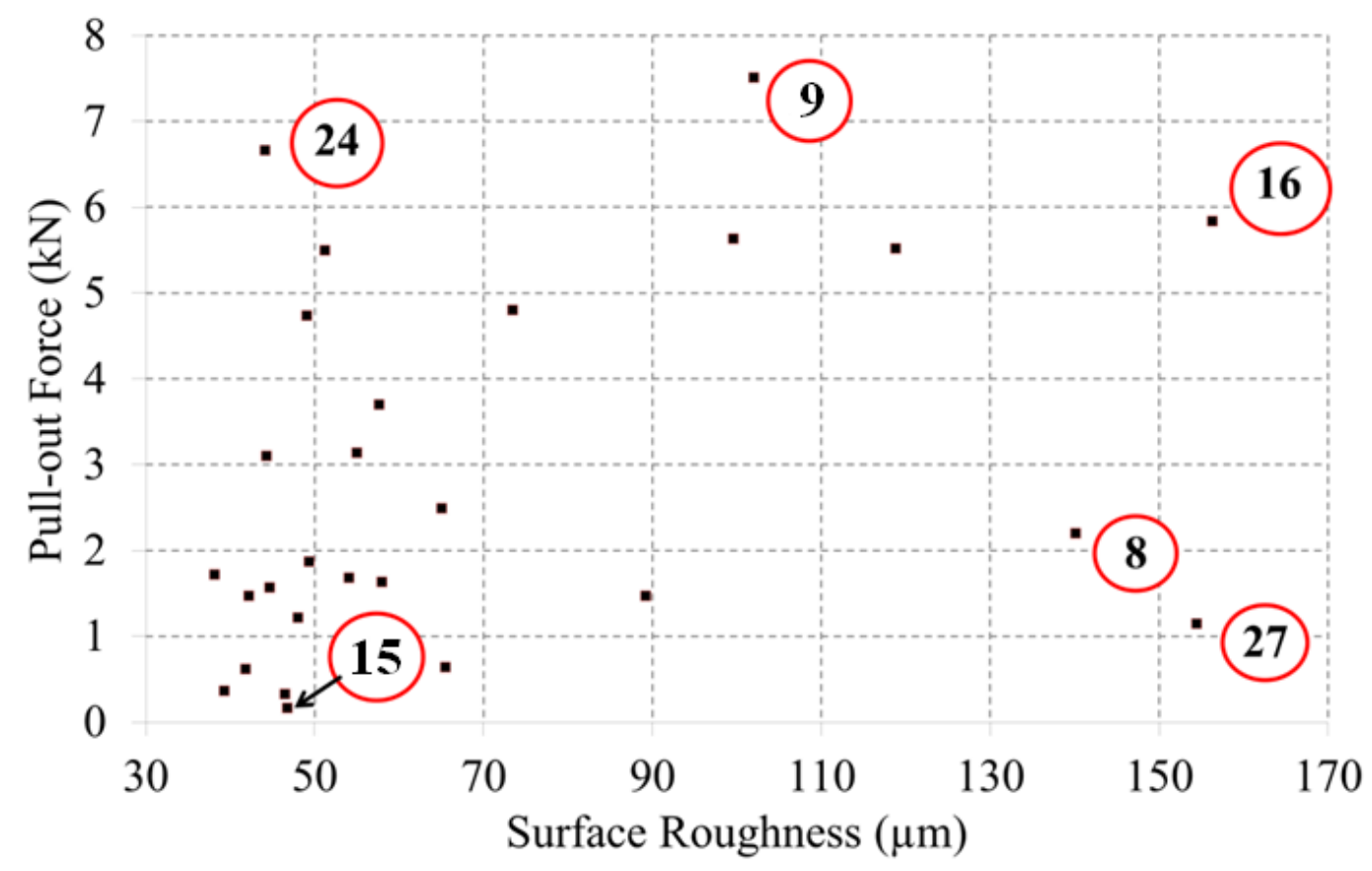

Figure 19 Distribution of the full DoE set of samples showing the surface roughness versus the pull-out force, with DoE sample numbers indicated for a number of key samples which are discussed in the text. 
While the pin removal force is not solely reliant on surface roughness, the distribution of the samples in this graph indicates that the majority of the samples produced with low surface roughness exhibited low removal force. A similar trend was observed in a work by Yang et al, where roughness was found to correlate with bond strength (Yang et al., 2001). Yang et al examined this effect in more detail in a subsequent work, showing that while the roughness can lead to a loss in interference due to the valleys of the rough texture, the plastic deformation of the asperities in the texture can lead to increased contact pressure, and thus an increased bond strength (Yang et al., 2002).

Moreover, an interesting contrast was noted for some samples with high surface roughness which resulted in low removal force. Samples 9 and 15 presented an average surface roughness of 102 and $46 \mu \mathrm{m}$, melt depth of 1.25 and $0.2 \mathrm{~mm}$, and resulted in the maximum and minimum removal force of 7.51 and $0.17 \mathrm{kN}$ respectively. This could be explained by the low frequency used in sample 9 which leads to a longer heating time. The longer residence time in turn leads to larger heat affected zone (HAZ) and the creation of the hard lattice martensite residing on the soft and low strength austenite, see Figure 16.

The highest removal forces found in the DoE compare well to standard commercial interference fasteners. The standard $10 \mathrm{~mm}$ diameter case hardened mild steel dowel and corresponding 9.99 $\mathrm{mm}$ ring tested for comparison gave an average removal force of $6.72 \mathrm{kN}$ for seven repeated samples. The highest average value found for a laser textured $10 \mathrm{~mm}$ diameter pin inserted into a $10.05 \mathrm{~mm}$ ring was $6.79 \mathrm{kN}$, found for sample 9. The 95\% confidence intervals were $2.20 \mathrm{kN}$ and $1.61 \mathrm{kN}$, for the standard dowel and sample 9. respectively. The removal force for the commercial dowels drops off linearly after the initial peak. For the laser textured fasteners however, the force remained high after the initial peak, typically about half of the peak value, and in many cases the force increased towards the end of the removal, to close to or even exceeding the initial peak force.

The removal force peaks were of comparable values and confidence, with the laser textured sample giving a slightly higher force at a slightly smaller $95 \%$ confidence interval. The laser textured samples also present a number of advantages. The tendency for the removal force to remain high after the initial failure would find important application in safety critical applications. With laser texturing, the fit can be localized by texturing a specific portion of a 
shaft. Control of the diameter via laser texturing also eliminates the need for precision machining of the part. The laser parameters can also be chosen to give a specific texture, and thus a specific force, from the same initial diameter pin.

\subsection{Modified surface hardness}

A very limited enhancement in surface micro-hardness was noted on some of the produced samples; see Figure 20, with no strong relationship that can be established for the effect of the processing parameters. Stainless steels in general are not conducive to laser hardening, due to the low carbon content and the short processing time (Kato et al., 2006).

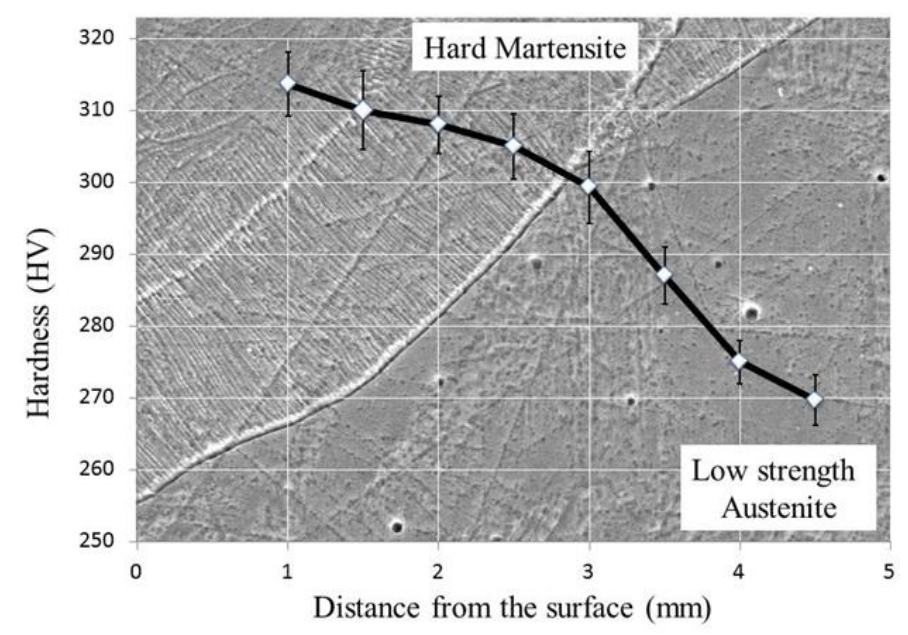

Figure 20 The micro-hardness measured from the surface to the bulk material of sample 9 .

The low carbon content in stainless steel does not allow for the significant change in the microhardness during the laser processing, therefore high elevated temperatures and longer treatment time is necessary to allow for the diffusion of carbon. Laroudie et al. published a study on the case hardening of stainless steel by using laser alloying elements and pre-deposited materials, i.e. $\mathrm{TiC}$ and $\mathrm{SiC}$ (Laroudie et al., 1994). In the case of sample 15, the short pulse width did not allow for the deep melting of the material or reaching high surface temperatures and no phase change was resulted as shown in Figure 17. The re-solidified surface layer only exhibits change in the grains orientation with no significant change in the size. 


\subsection{Effect of the frequency on the measured outputs}

The effect of the pulse repetition frequency (PRF) on the surface morphology, microstructure and ablation of the laser processed material has been reported by many researchers. Schaffer et al. (Schaffer et al., 2001) stated that heat builds up from the pulsed laser thermal energy only when the time intervals between successive pulses is shorter than the thermal diffusivity of the material. Taking this in account and assuming the thermal diffusivity of $316 \mathrm{~L} \mathrm{SST}, \alpha=3.8 \times 10-6$ $\mathrm{m}^{2} / \mathrm{s}$ and laser beam focus size of $200 \mu \mathrm{m}$, would result in a diffusion time of $8 \mathrm{~ms}$. Since the full DoE test was performed in a range of pulse width of $1.6-5 \mathrm{~ms}$, no extreme melting or material ablation was resulted.

The cold-drawn, austenitic, (FCC) microstructure of the 316L SST at the room temperature is a ductile and low strength alloy, with large variation in the hardness and elastic modulus. This variation can result from the cold work during manufacturing. Compared to other types of steel, the thermal processing and hardening of austenitic stainless steel and undergoing phase transformation does not always result in residual surface stresses, and only small or negligible change in the surface micro-hardness can be measured. When the localized molten material resolidifies and the surrounding (HAZ) that reached the phase transformation temperature cools and transform to martensite, the softer austenite in the bulk material plastically deforms and compensates the expansion and the volume change associated with the formation of martensite. Due to the aforementioned effects, there was no sign of surface residual stresses noted and the fluctuation in the nano-hardness and the elastic modulus was symmetrical around the average values when measured both at the surface and near the untreated center, see Figure 10. The maximum enhancement in the surface hardness was noted in sample 9 and was not very significant: from 270 to $313 \mathrm{HV}$, see Figure 20.

Also, from the insertion-removal test for samples 15 and 24, which show the same surface roughness, removal forces of 0.17 and $6.66 \mathrm{kN}$ were found, respectively, see Figure 19. This can be explained by the differences in the frequency, which produced a hard surface layer on sample $24(300 \mathrm{~W}, 100 \mathrm{~Hz}, 20 \%)$, compared to a brittle lamella surface on sample 15 which can be removed during the insertion. From Figure 11 and Figure 12, and the response surfaces are shown in Figure 13 and Figure 14, the processed samples exhibited a range of 10 to $47 \mathrm{kN}$ for the insertion force and 0.1 to $7.5 \mathrm{kN}$ for the pull out force respectively. This variation could be 
explained by the alteration in the resulting mechanical properties of the processed surface and not only the increase in the diameter as explained earlier. For example, points A and B in Figure 14 (b) and (c) belong to samples $16(500 \mathrm{~W}, 100 \mathrm{~Hz}$, and $0 \%)$ and $23(500 \mathrm{~W}, 100 \mathrm{~Hz}, 20 \%)$ and they both have similar diameter increase of 0.75 and $0.8 \mathrm{~mm}$, respectively. It was noted that sample 16 exhibits a removal force of $5.7 \mathrm{kN}$ before failure while sample 23 fails at $1.4 \mathrm{kN}$. The reduction in the pull out force in sample 23 is caused by the positive overlapping scans, in which the laser beam re-melts the surface material which already been processed during the previous scan resulting in a higher surface temperature. The subsequent high cooling rate results in a hard and brittle lamellar surface microstructure, which tends to break and destroyed during insertion. Moreover, the lower roughness of $89 \mu \mathrm{m}$ in sample 23 would contribute to a reduction of the friction force. The failure mechanism for all the samples indicates high joint bond strength between the insertion and the hub which persists and even strengthens further during pull-out, as can be seen in Figure 11 (b) and Figure 12 (b). Rather than a complete, immediate failure of the joint this is effectively a re-griping of the joint before total failure. This is beneficial for providing a safer joint compared to conventional joints. An additional safety factor is evident due to the extended displacement provided from these joints before joint failure.

The inverse relationship between the frequency and the measured responses; the increase in diameter, the insertion and pull-out forces, has a strong and significant correlation as can be seen from the (r) and (p) values listed in Table 2. It was particularly noted that increasing pulse frequency results in a reduction in the bonding forces. The higher frequency of $300 \mathrm{~Hz}$ resulted in smaller increase in the samples diameter, and lower level of surface roughness, due to the short heating time. Also, a similar correlation was found between the frequency and the resulting surface roughness. The lower the frequency the longer the heating time and the larger the melt pool depth and width, which produced a higher surface roughness. The increased melt liquid, with the aid of the assist gas jet and the centrifugal force generated from the high rotational speed combine in this case to create more rough and variable surface profile. This conclusion also agrees with the results plotted in Figure 8. The maximum Ra was reached at the residence time of $3 \mathrm{~ms}$ and the irradiance of $8.26 \mathrm{~kW} / \mathrm{mm}^{2}$. A steep degradation in the surface roughness was noted when exceeding these values due to the over melting and resulting flow of the liquid melt. 


\section{Conclusion}

The aim of this study was to characterize a new method for producing interference-fit joints with highly controlled bond strength. The effect of the laser processing parameters on the joint performance were investigated and these were found to be highly repeatable, with a high level of control on the modified layer thickness, the increase in diameter, and the resulting mechanical properties. The bond strengths, and confidence intervals, were found to be comparable to those of a standard steel dowel interference joint. The bond joint was found to re-grip at high force levels after initial failure, providing more secure joint and increased safety. This joining method allows for the possibility of joining different materials, the creation of localized fit regions along a shaft, and eliminating of the typical need for interference fits of high precision machining of the outer diameter. Control of the input parameters can give a defined texture and outer diameter, and thus a specific bond strength, for the same initial pin diameter. The pulse repetition frequency is the most significant processing parameter for control of the resulting mechanical properties and the bond strength with a clear inverse relationship. The modified surface layer did not reveal any distinct variation in the elastic modulus or hardness across the cross section of the insertion. This paper provides a method to optimize the main laser input parameters, the resulting surface roughness, the diameter increase, the force required for joint assembly, and prediction of the maximum joining force.

\section{Acknowledgments}

The authors would like to thank the funding agency Enterprise Ireland for funding this work under grant CF/2014/2619. 


\section{References}

ASM Handbooks, 1985. Vol. 9 Metallography and Microstructures. ASM Int. Met. Park. OH.

Barter, S., Dixon, B., 2009. Investigation using quantitative fractography of an unexpected failure in an F/A-18 centre fuselage bulkhead in the FINAL teardown program. Eng. Fail. Anal. 16, 833-848. doi:10.1016/j.engfailanal.2008.07.008

Bergström, D., Powell, J., Kaplan, A.F.H., 2007. The absorptance of steels to Nd:YLF and Nd:YAG laser light at room temperature. Appl. Surf. Sci. 253, 5017-5028. doi:10.1016/j.apsusc.2006.11.018

Chikarakara, E., Naher, S., Brabazon, D., 2011. Analysis of Microstructural Changes during Pulsed CO2 Laser Surface Processing of AISI 316L Stainless Steel. Adv. Mater. Res. 264$265,1401-1408$.

Fu, Y., Ge, E., Su, H., Xu, J., Li, R., 2015. Cold expansion technology of connection holes in aircraft structures: A review and prospect. Chinese J. Aeronaut. 28, 961-973. doi:10.1016/j.cja.2015.05.006

Huyuk, H., Music, O., Koç, A., Karadogan, C., Bayram, Ç., 2014. Analysis of elastic-plastic interference-fit joints. Procedia Eng. 81, 2030-2035.

Kannatey-Asibu, E., 2009. Principles of Laser Materials Processing. Wiley \& Sons, Hoboken, New Jersey.

Kato, H., Takahashi, M., Ikeuchi, K., 2006. Nanoindentation Hardness Test for Estimation of Vickers Hardness. Trans. JWRI 35, 57.

Khan, P.A.A., Debroy, T., 1985. Absorption of CO 2 laser beam by AISI 4340 steel. Metall. Mater. Trans. B 16, 853-856.

Laroudie, F., Tassin, C., Pons, M., 1994. Laser surface alloying of 316L stainless steel: different hardening routes and related microstructures. Le J. Phys. IV 4, C4-77-C4-80.

Mattox, D.M., 2010. Handbook of physical vapor deposition (PVD) processing. William Andrew.

Norton, R.L., 2011. Machine Design, 4th ed. Pearson Education, New Jersey.

Obeidi, M.A., McCarthy, E., Brabazon, D., 2016. Methodology of laser processing for precise 
control of surface micro-topology. Surf. Coatings Technol. 307, 702-712. doi:10.1016/j.surfcoat.2016.09.075

Parmley, R.O., 1989. Standard handbook of fastening and joining. McGraw-Hill Companies.

Pinkerton, A.J., Li, L., 2003. An investigation of the effect of pulse frequency in laser multiplelayer cladding of stainless steel. Appl. Surf. Sci. 208, 405-410.

Rosenkranz, A., Reinert, L., Gachot, C., Mücklich, F., 2014. Alignment and wear debris effects between laser-patterned steel surfaces under dry sliding conditions. Wear 318, 49-61. doi:10.1016/j.wear.2014.06.016

Schaaf, P., 2002. Laser nitriding of metals. Prog. Mater. Sci. 47, 1-16.

Schaffer, C.B., Brodeur, A., Mazur, E., 2001. Laser-induced breakdown and damage in bulk transparent materials induced by tightly focused femtosecond laser pulses. Meas. Sci. Technol. 12, 1784-1794. doi:10.1088/0957-0233/12/11/305

Shizhen, W., Cuiyun, L., Ruolin, W., Chaoli, M., 2015. Effect of Cold Expansion on High Cycle Fatigue of 7A85 Aluminum Alloy Straight Lugs. Rare Met. Mater. Eng. 44, 2358-2362. doi:10.1016/S1875-5372(16)30020-0

Szkodo, M., Bie, A., 2016. Surface \& Coatings Technology In fl uence of laser processing of the low alloy medium carbon structural steel on the development of the fatigue crack $296,117-$ 123. doi:10.1016/j.surfcoat.2016.04.032

Waugh, D.G., Lawrence, J., 2015. Laser Surface Engineering: Processes and Applications.

Yang, G.M., Coquille, J.C., Fontaine, J.F., Lambertin, M., 2002. Contact pressure between two rough surfaces of a cylindrical fit. J. Mater. Process. Technol. 123, 490-497. doi:10.1016/S0924-0136(02)00139-5

Yang, G.M., Coquille, J.C., Fontaine, J.F., Lambertin, M., 2001. Influence of roughness on characteristics of tight interface fit of a shaft and a hub. Int. J. Solids Struct. 38, 7691-7701. doi:10.1016/S0020-7683(01)00035-X

Yasavol, N., Abdollah-zadeh, a., Ganjali, M., Alidokht, S. a., 2013. Microstructure and mechanical behavior of pulsed laser surface melted AISI D2 cold work tool steel. Appl. Surf. Sci. 265, 653-662. doi:10.1016/j.apsusc.2012.11.070. 